\title{
Environmental Enrichment as an Effective Treatment for Autism: A Randomized Controlled Trial
}

\author{
Cynthia C. Woo and Michael Leon \\ University of California Irvine
}

\begin{abstract}
Enriched sensorimotor environments enable rodents to compensate for a wide range of neurological challenges, including those induced in animal models of autism. Given the sensorimotor deficits in most children with autism, we attempted to translate that approach to their treatment. In a randomized controlled trial, 3-12 year-old children with autism were assigned to either a sensorimotor enrichment group, which received daily olfactory/tactile stimulation along with exercises that stimulated other paired sensory modalities, or to a control group. We administered tests of cognitive performance and autism severity to both groups at the initiation of the study and after 6 months. Severity of autism, as assessed with the Childhood Autism Rating Scale, improved significantly in the enriched group compared to controls. Indeed, $42 \%$ of the enriched group and only $7 \%$ of the control group had what we considered to be a clinically significant improvement of 5 points on that scale. Sensorimotor enrichment also produced a clear improvement in cognition, as determined by their Leiter-R Visualization and Reasoning scores. At 6 months, the change in average scores for the enriched group was 11.3 points higher than that for the control group. Finally, $69 \%$ of parents in the enriched group and 31\% of parents in the control group reported improvement in their child over the 6-month study. Environmental enrichment therefore appears to be effective in ameliorating some of the symptoms of autism in children.
\end{abstract}

Keywords: autism, enriched environment, sensory stimulation, olfaction, tactile

Autism is expressed as a social-behavioral disorder, often accompanied by communication difficulties, maladaptive behaviors, cognitive dysfunction, motor problems, seizures, gastrointestinal distress, and anxiety. While significant improvement in autism symptoms has been reported following intensive early behavioral interventions, these expensive approaches are typically effective to some degree for some children, and only if initiated early in life (Warren et al., 2011). Here, we have used a low-cost therapeutic approach that ameliorates many symptoms of autism in a significant proportion of the affected children in our study. This treatment also benefits autistic children who are past the age at which other treatments are effective.

Cynthia C. Woo and Michael Leon, Department of Neurobiology and Behavior, the Center for Autism Research and Treatment, University of California Irvine.

The study was conducted at the Institute for Clinical and Translational Sciences at UC Irvine (Grant UL1 TR000153). We thank the Nancy Lurie Marks Family Foundation, Eyal and Yael Aronoff, the Samueli Foundation and the William and Nancy Thompson Family Foundation for their support. The Aronoffs subsequently invested in a company that offers this treatment, from which the authors receive no financial compensation. We also thank Harold Dyck, Robert Newcomb, and Rita Petersen for assisting with the statistical analyses, and Ira Lott, Christy Hom, and Edna Hingco for their help.

Correspondence concerning this article should be addressed to Michael Leon, Department of Neurobiology and Behavior, 2205 McGaugh Hall, University of California Irvine, Irvine, CA 92675-4550. E-mail: mleon@uci.edu

\section{Sensorimotor Enrichment Ameliorates the Consequences of Neurological Challenges, Including in Animal Models of Autism}

In the wild, rodents live in complex social systems and navigate through complex burrow systems from which they venture to forage for a wide variety of foods (Calhoun, 1950; Hurst \& Barnard, 1992). However, when they are studied in the lab, they are typically kept isolated in a plain box cage. This lack of stimulation in the lab does not seem to lead to any obvious neurobehavioral problems, as they engage in normal social behavior under test conditions, rear their young, solve cognitive problems, and have no obvious motor deficits. The lack of such deficits could suggest that the effects of environmental stimulation on neurobehavioral function may be minimal. To the contrary, neurobehavioral development is greatly impacted when sensory input is further decremented (Bengoetxea et al., 2012; Ghoshal, Pouget, Popescu, \& Ebner, 2009; Guthrie, Wilson, \& Leon, 1990; MayaVetencourt \& Origlia, 2012; Noppeney, 2007), indicating that the brain does depend on sensory stimulation for normal development.

If decreased sensorimotor experiences impair neurobehavioral function, then one might expect that increasing sensorimotor stimulation would enhance neurobehavioral function. In fact, enriched sensorimotor experiences reliably enhance dendritic branching, synaptic density, and neurogenesis (van Praag, Kempermann, \& Gage, 2000; Nithianantharajah \& Hannan, 2006). Additionally, enhanced environmental stimulation ameliorates the effects of a wide range of neurological challenges that are experimentally produced in animals. These challenges include: brain lesions, toxin exposure, exposure to addictive drugs, brain trauma, stroke, seizures, aging, and hypoxia (Laviola, Hannan, Macri, Solinas, \& 
Jaber, 2008; Nithianantharajah \& Hannan, 2006; Pang \& Hannan, 2013). In animal models, enriched sensorimotor experience also ameliorates genetically based neurological disorders such as Down's syndrome, Alzheimer's disease, Huntington's disease, Parkinson's disease, schizophrenia, and autism (Laviola et al., 2008; Nithianantharajah \& Hannan, 2006; Pang \& Hannan, 2013).

In humans, autism has a clear but complex genetic basis (Abrahams \& Geschwind, 2008; Freitag, 2007; Freitag, Staal, Klauck, Duketis, \& Waltes, 2010) and some children have autistic symptoms that are associated with a known gene mutation or chromosomal aberration (Freitag, 2007). Mouse models have been generated to mimic some of these genetic variants (Ey, Leblond, \& Bourgeron, 2011) and a subset of these mouse models of autism have had their symptoms reversed or ameliorated following exposure to an enriched environment.

For example, mice have been given a Mecp2 (tm1Tam)-null allele to model the genetic abnormality of Rett syndrome. This genetic anomaly results in the deterioration of cognitive and motor skills in early childhood in humans, similar to some behavioral symptoms seen in children with autism. Enriched sensorimotor experience was found to improve motor coordination and anxietyassociated traits in heterozygous Mecp2+/- mice (Kerr, Silva, Walz, \& Young, 2010; Kondo et al., 2008; Nag et al., 2009). Sensorimotor enrichment for these mice produced changes in both excitatory and inhibitory synaptic densities in cerebellum and cortex (Lonetti et al., 2010). Additionally, it restored normal long-term potentiation in cortex, increased cortical BDNF levels, improved memory, and altered several synaptic markers in these mice (Kerr et al., 2010; Lonetti et al., 2010). Fragile X syndrome, which arises with a mutation of the FMRl gene, also shares symptoms with autism. Sensorimotor enrichment similarly rescues Fmrl-knockout mice from cognitive deficiencies (Restivo et al., 2005).

Potocki-Lupski syndrome involves the microduplication of band 11.2 on the short arm of chromosome 17 and $70-90 \%$ of humans with this syndrome are diagnosed with autism (Potocki et al., 2007). The mouse model of this syndrome has social abnormalities, abnormal ultrasonic vocalizations, perseverative and stereotypic behaviors, anxiety, deficits in learning and memory, as well as motor deficits (Lacaria, Spencer, Gu, Paylor, \& Lupski, 2012). Rearing these mice in an enriched environment ameliorated the motor deficits, improved learning and memory deficits, reduced aggressive behavior, and relieved anxiety, although it did not affect their social abnormalities or their abnormal vocalizations (Lacaria et al., 2012).

Finally, Schneider, Turczak, and Przewlocki (2006) exposed fetal rats to valproic acid to produce another animal model of autism. Sensorimotor enrichment decreased repetitive/stereotypic activity and anxiety, while increasing exploratory activity and social behaviors. Similar enhancements in social behavior were observed between control rats given enriched sensorimotor experience and control rats reared in a standard box cage. They concluded that environmental enrichment could be a potential treatment for autism.

\section{Sensory Abnormalities in Autism}

The presence of sensory processing dysfunction contributes to the daily challenges of children with autism (Hilton et al., 2010;
Kern et al., 2007; Leekam, Nieto, Libby, Wing, \& Gould, 2007; Tomchek \& Dunn, 2007; Watling, Deitz, \& White, 2001). Indeed, more than $90 \%$ of those with autism have sensory abnormalities, expressed as oversensitivity, unresponsiveness, or sensory-seeking behaviors, which persist across all ages and IQ levels (Ben-Sasson et al., 2009; Hilton et al., 2010; Kern et al., 2007; Leekam et al., 2007; Tomchek \& Dunn, 2007; Watling et al., 2001).

The most commonly observed sensory issues in autism involve olfaction and touch sensitivity (Hilton et al., 2010; Lane, Young, Baker, \& Angley, 2010; Leekam et al., 2007; Schoen, Miller, Brett-Green, \& Nielsen, 2009). Not only is sensory processing dysfunction correlated with both maladaptive behaviors and autism severity (Kern et al., 2007; Lane et al., 2010), but touch and olfactory issues are strong predictors of both atypical social behaviors and poor social communication skills in children with autism (Bennetto, Kuschner, \& Hyman, 2007; Hilton et al., 2010).

\section{Sensorimotor Deprivation Increases Autism Symptoms}

If sensorimotor experiences can alter the probability of expressing autistic symptoms, as was observed in animal models of autism, then reducing the amount of environmental stimulation should increase their expression. Conversely, increasing such stimulation should decrease the expression of these symptoms. A natural experiment of this kind occurred when impoverished Romanians sent large numbers of children to orphanages, where they had little environmental stimulation. Consequently, one third of them developed what has been called postinstitutional autistic syndrome (Hoksbergen, ter Laak, Rijk, van Dijkum, \& Stoutjesdijk, 2005). This syndrome includes stereotypic behaviors, an inability to identify human emotions, as well as disordered communication, language, cognition, and attachment (Ellis, Fisher, \& Zaharie, 2004; Hoksbergen et al., 2005; Johnson, Browne, \& Hamilton-Giachritsis, 2006; Miller, Chan, Comfort, \& Tirella, 2005; Wismer Fries, Ziegler, Kurian, Jacoris, \& Pollak, 2005). Importantly, when these orphans were moved to an enriched environment provided by foster parents, their intelligence test scores, language development, social engagement and mental health improved (Nelson et al., 2007). Therefore, environmental deprivation can increase the probability of expressing a syndrome that is quite similar to autism, and environmental stimulation can ameliorate those symptoms.

\section{Olfactory/Tactile Pairings Alter Neurobehavioral Development}

The combination of olfactory and tactile stimulation may be particularly compelling for the developing brain. When we gave olfactory/tactile stimulation to human infants on the first day of life, they developed an attraction to that odor, while odor exposure alone was ineffective in that regard (Sullivan et al., 1991). We also found striking behavioral, neuroanatomical, neurophysiological and neuropharmacological changes in the brains of young rats when they were exposed to simultaneous olfactory/tactile stimulation (Coopersmith \& Leon, 1984; Rangel \& Leon, 1995; Sullivan, Wilson, \& Leon, 1989; Wilson, Sullivan, \& Leon, 1987; Woo \& Leon, 1991; Woo, Coopersmith, \& Leon, 1987). Again, olfactory stimulation alone did not evoke neurobehavioral plasticity in developing rats. 
Since the combination of olfactory and tactile stimuli was particularly effective in producing neurobehavioral changes in young rats, we used a sensorimotor regimen that involved olfactory and tactile stimulation, as well as various combinations of visual, thermal, motor, balance, auditory stimuli, and cognitive tasks, in an attempt to maximize sensorimotor stimulation in humans. We also wanted to add novelty into their sensorimotor experience both by cycling through a set of seven odorants and by introducing new enrichment activities at regular intervals. Indeed, novelty appears to be a critical aspect of the environmental enrichment. Veyrac et al. (2009) found that exposing mice to different odorants on a daily basis increased memory and neurogenesis, whereas exposing them to a complex combination of odorants that did not vary over the exposure period was not effective. We therefore had parents give novel sensorimotor enrichment with simultaneous stimulation of different sensory systems to children with autism each day for 6 months, in addition to their ongoing standard care, and we then determined whether their symptoms improved compared to standard care controls.

\section{Method}

We conducted a randomized controlled trial involving 28 male children diagnosed with autism, 3-12 years old (mean $+/-S D$, $6.6+/-2.5$ years). The Institutional Review Board at the University of California, Irvine approved all procedures used in this study. Children were excluded from the study if they had syndromic forms of autism, such as Rett's Disorder, Fragile X syndrome, or Childhood Disintegrative Disorder. No psychotropic medications were allowed throughout the study and anticonvulsant medication was only allowed if the child had been on a stable dose longer than 3 months prior to the initiation of the study. Children could not have initiated a new in-school behavioral therapy within one month before the start of the study or two months before the study for a private program. No sensory integration therapy was permitted at any time during the study. We also did not allow concurrent therapies that involved physical restraint. Behavioral therapies were so widely utilized by the children that we referred to their usage as "standard care," and the frequency of use for the different behavioral therapies did not differ statistically across groups (see Table 1). Diagnoses of autism were confirmed using the Autism Diagnostic Observation Schedule (ADOS). The communication and social interactions ADOS scores were combined, and to qualify for our study, the total score had to be within the ADOS autism classification and not simply within the autism spectrum classification. The children were then randomly assigned to either a sensorimotor enrichment group + standard care (13 children), or a group receiving standard care alone (15 children), matching for age and autism severity, as assessed by their Childhood Autism Rating Scale (CARS) score.

The children in both the sensorimotor enrichment group and the control group all were receiving various combinations of standard treatments, which were continued throughout the clinical trial (see Table 1). Most children were receiving applied behavior analysis, which involved differential reinforcement for adaptive behavior. Some children in both groups also received concurrent speech therapy to improve their language skills, occupational therapy to help develop the skills needed for independent living, or social skills therapy in an effort to develop the ability to experience typical social interactions. Adapted physical education provided motor activities that were modified for children with autism. Physical therapy was used to improve both fine motor skills and gross motor skills.

The enrichment group received daily exposure to multiple sensorimotor stimuli, distributed throughout the day. Parents in this group were supplied with a kit that contained most of the supplies needed for the sensorimotor exercises. For olfactory enrichment, each kit included seven vials containing scented essential oils (anise, apple, hibiscus, lavender, lemon, sweet orange, and vanilla; Essential Oils, Portland, OR), seven empty vials with caps, and cotton balls. For different textures, the kit contained squares of plastic doormat, smooth foam, a rubber sink mat, aluminum foil, fine sandpaper, felt, and sponges. For different objects to manipulate, they were given a small piggy bank with plastic coins, miniature plastic fruits, colored beads, a small fishing pole with a magnetic "hook," colorful paper clips, a large button, and $20+$ small toys of varying shapes/colors/textures. In addition, the kit contained straws, colored construction paper, four bowls for water, pictures of well-known paintings, pictures of fruits, and a can of Play-Doh. For music enrichment, they were provided with a classical music CD (Classical Music For People Who Hate Classical Music, Vol. 1; Direct Source) and a portable CD player with headphones. The parents provided a wooden plank $\left(2^{\prime \prime} \times 8^{\prime \prime} \times\right.$ $\left.5^{\prime}\right)$ for a walking exercise, scented bath soap and body oils for the spa treatment exercise, and miscellaneous other household items for the exercises, including a large salad bowl for water at different temperatures, metal spoons, ice, blindfold, noise maker (e.g., a bell or buzzer), picture book, cookie sheet, oven dish, mirror, ball or pillow, pillowcase, felt-tip markers, and music that matched pictures (e.g., Hawaiian music and a beach picture). They also pro-

Table 1

Standard Treatments Received by Children in Both Sensorimotor Enrichment Group and Control Group

\begin{tabular}{lccc}
\hline \multicolumn{1}{c}{ Concurrent Interventions } & $\begin{array}{c}\text { Standard care } \\
(n=15)\end{array}$ & $\begin{array}{c}\text { Sensory enrichment } \\
(n=13)\end{array}$ & $P$ value* \\
\hline Speech therapy & $12 / 15$ & $10 / 13$ & 0.84 \\
Occupational therapy & $9 / 15$ & $7 / 13$ & 0.75 \\
Applied behavioral analysis & $10 / 15$ & $10 / 13$ & 0.60 \\
Social skills & $2 / 15$ & $2 / 13$ & 0.86 \\
Adapted physical education, physical therapy, other. & $8 / 15$ & $4 / 13$ & 0.25 \\
\hline
\end{tabular}

* Two-sample test of proportions 
vided material to create a multitextured walking path, such as carpet, a hard floor, pillows, cardboard, or bubble wrap.

The children were exposed to four different fragrances, at different times during the day. The parent placed one drop of odorant on a cotton ball that they had placed in a glass vial and they then allowed the child to sniff it repeatedly for a minute. This olfactory stimulation was paired with gentle tactile stimulation, given by rubbing their backs with a closed hand. They also were exposed to a fragrance throughout the night by placing a scented cotton ball in their pillowcase before bedtime. Parents were asked to cycle through each of the seven odorants, which were chosen solely based on their pleasant fragrance. Only occasionally did children dislike an odorant, and in those cases, we provided them with another pleasant odorant (banana or apple blossom; Essential Oils, Portland, OR).

The children listened to classical music once a day and the parents were asked to use the portable CD player and the headphones that were included in their kit to pair auditory and tactile stimulation. However, the children typically would not use the headphones and parents used speaker systems to expose their child to the music. In addition, the parents were given written instructions for 34 sensorimotor enrichment exercises, and after a brief training session, they engaged their child with 4-7 exercises, twice a day. These exercises involved somewhat arbitrary combinations of sensory stimuli such as tactile, thermal, visual, and motor activities. We instructed the parents to engage in a different set of exercises every 2 weeks and the exercises became increasingly challenging over the course of 6 months. The daily exercises took approximately 15-30 minutes to complete, twice a day: 1 . The child places his or her hands or feet in water of different temperatures (thermal, motor), 2. The child squeezes objects of different shapes and textures (tactile, motor), 3. The parent draws lines on the child's hand with objects of different texture while the child watches (tactile, visual), 4. The blindfolded child walks on a pathway of different textures (tactile, motor), 5. The parent draws imaginary lines on the child's face, arms, and legs with objects having different textures while music plays (tactile, auditory), 6 . The child selects the twin of objects in a pillowcase after seeing it on the table (tactile, cognitive), 7. The child is given a scented bath and a massage with scented oil (thermal, tactile, olfactory), 8. The parent touches the child on his or her arms and legs with a cooled spoon or warmed spoon while the parent speaks or sings (thermal, auditory, tactile), 9. Lines are drawn on the child's arms and legs with cooled or warmed spoons (thermal, tactile), 10. The child is shown a picture of an object and picks out the real object on a table among other objects (visual, cognitive, motor), 11. The child is asked to walk on a $2^{\prime \prime} \times 8^{\prime \prime} \times 5^{\prime}$ board, then he or she is asked to do that task blindfolded (motor, balance), 12. The child picks out a colored bead among a plate full of ice cubes (thermal, motor, visual), 13. The child is shown a photo and his or her attention is drawn away from the photo using an auditory cue (visual, auditory), 14. The child lifts an object out of a cool bowl of water and then a warm bowl of water (motor, thermal, visual), 15. The child pulls a button from between the parent's fingers (motor, tactile, visual), 16. The child walks either on a sheet of foam or on large pillows, eventually blindfolded (tactile, balance, motor), 17. The child points to objects in a book and says the name of the object (language, cognitive, motor), 18. The child's finger is placed on a cool object and then a warm object (thermal, tactile), 19. The child pokes a hole in Play-Doh and then places grains of rice in it (motor, tactile, visual), 20. The child selects a texture square that matches the texture of an object in a photo (tactile, cognitive, visual), 21. Different objects are used to draw imaginary circles on the child's face (tactile, cognitive), 22. The child places cold straws filled with ice in Play-Doh using each hand (motor, thermal, visual), 23. The child walks on a $2^{\prime \prime} \times 8^{\prime \prime} \times 5^{\prime}$ board while holding a cooled tray (thermal, balance, motor), 24. The parent rubs each of the child's fingers and toes in turn, while the child watches (tactile, visual), 25. The child places coins in a piggy bank using only his or her reflection in a mirror (motor, cognitive, visual), 26. The child uses a magnet on the end of a small fishing line to pick up paper clips (motor, visual), 27. The child tracks a red object that is moved around a photo of a painting (visual, cognitive), 28. The child walks up and down stairs while holding a big ball or pillow (motor, tactile, balance), 29. The child draws shapes using pen and paper while the parent draws imaginary shapes on the child's back using a toy (motor, tactile, visual), 30. The child draws lines using both hands simultaneously (motor, cognitive, visual), 31. The child matches the color of objects in a photo with colored beads (visual, cognitive, motor), 32. The child blows a small piece of aluminum foil on the floor as far as possible (motor, visual), 33. The child views a picture moving first behind and then in front of another picture (visual, cognitive), 34. The child views a photo with music associated with that scene (auditory, visual).

Trained psychometricians conducted all assessments blind with respect to group assignment, both at the beginning of the study and after 6 months. All individuals were tested with the Leiter International Performance Scale-Revised (Leiter-R), a nonverbal test of cognitive abilities, which is recommended for testing children with autism (Tsatsanis et al., 2003). This test can evaluate changes in nonverbal cognitive ability. The Leiter- $\mathrm{R}$ does not require a spoken or written word from the examiner or the child, allowing the study of cognitive performance in children with and without language issues. Since the Leiter-R scores do not change significantly with increasing age, the test can be used effectively with children from 2-21 years. The test can measure cognitive ability over a wide range and it also allows experimenters to observe improvement in cognitive capacities over time.

We used the Expressive One-Word Picture Vocabulary Test to assess verbal intelligence and auditory-visual-verbal association skills. The children were shown a picture of an item and were then requested to name the item using one word.

The CARS provides qualitative measures of a large range of issues for children with autism (Schopler, Reichler, DeVellis, \& Daly, 1980). The test assesses: relating to people, imitation, emotional response, emotional expression, body use, object use, adaptation to change, visual response, listening response, taste, smell, and touch responses, fear or nervousness, verbal communication, nonverbal communication, activity level, level and consistency of intellectual response, and general impressions. The CARS test combines total scores to place individuals in nonautistic, mildly/ moderately autistic, or severely autistic classifications. This test has very high internal consistency, indicating that the individual scores together constitute an effective tool for the identification of different levels of autism severity (Schopler et al., 1980). The CARS has $100 \%$ accuracy in discriminating children with autism from children with intellectual disabilities (Teal \& Wiebe, 1986).

Changes in test scores over 6 months were compared between the sensorimotor enrichment and standard care groups using an analysis 
of covariance (ANCOVA, one-tailed), controlling for baseline. A $p$ value of less than or equal to 0.05 was considered statistically significant. We used parametric statistics, as residual analysis showed the data for all measures was balanced. In addition, with regard to clinical improvement, Perry et al., (2008) demonstrated a clinically significant improvement using a 5-point or greater decrease on the CARS score. We used the same criterion to determine whether a clinically significant improvement occurred in our study.

\section{Results}

Statistically, baseline values for the two groups did not differ significantly on age, ADOS scores, CARS scores, Leiter-R scores, or Expressive One-Word Picture Vocabulary Test scores. After 6 months, however, the mean change in Leiter-R (Visualization and Reasoning) raw scores in the sensorimotor enrichment group was 11.3 points higher than that in the standard care group (Figure 1; ANCOVA, $t(20)=-2.62, p=.008$; mean Leiter-R test score + - S.E.M, sensorimotor enrichment: $48.46+/-5.52$ (baseline), $57.23+/-5.50$ (6 months); standard care: $46.20+/-6.36$ (baseline), $43.70+/-6.89$ (6 months).

Comparison between groups revealed that after 6 months, the change in mean autism severity scores, assessed by the CARS, differed between groups by 2.8 points (ANCOVA, $t(23)=1.98$, $p=.03$; mean CARS score $+/-$ S.E.M., sensorimotor enrichment: $34.38+/-0.72$ (baseline), $31.12+/-1.46$ (6 months);

\section{$\square$ Sensorimotor enrichment Standard care}

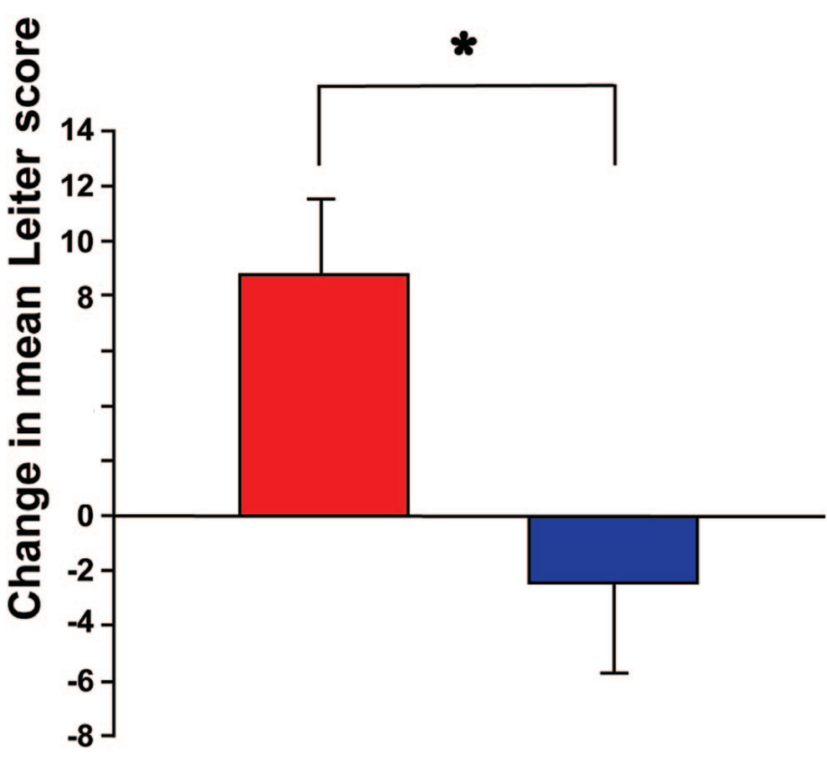

Figure 1. Change in mean Leiter-R score. Sensory enrichment results in improvements in cognitive function in children with full autism as measured using the Leiter International Performance Scale-Revised. A statistically significant improvement in the mean change in scores was observed in the sensorimotor enrichment group following 6 months of therapy, while the mean change in scores for the standard care group decreased over the same period of time. ${ }^{*}$ ANCOVA, $p=.008$. standard care: $38.07+/-1.71$ (baseline), $37.61+/-1.67$ (6 months). Moreover, $42 \%$ of the enriched group and $7 \%$ of the standard care group had what we considered to be a clinically significant improvement of at least 5 points on that scale (Figure 2; two-sample test for proportions, $p=.03$ ).

Parents were asked whether the overall autism symptoms of their child had improved, worsened, or stayed the same over the 6-month period. Statistical analysis was performed using the twosample test for proportions and the number of individuals reporting their child's autism symptoms had improved was compared to the number of individuals reporting their child's symptoms had worsened or had not change. A statistically significant increase in the number of parents reporting an improvement in autism symptoms was observed in the sensory enrichment group compared to the standard care group (Figure 3, Two sample test for proportions, $p=.03)$. Specifically, 69\% in the sensory enrichment group reported improvement, while $31 \%$ in the standard care group reported improvement.

We further analyzed the CARS scores to evaluate changes in specific behavioral responses. Although the change in overall total CARS score was statistically significant across the two groups, the average change in CARS scores for individual items did not reach statistical significance. However, greater improvement in behavioral responses was observed in the enriched group relative to the control group in 11 out of the 15 items examined on the test: relating to people; emotional responses; body use; object use; adaptation to change; visual response; listening response; taste, smell, and touch response and use; fear or nervousness; level of consistency of intellectual response; and general impressions. For example, we calculated the difference for the touch/smell/taste subtest of the CARS between the initial test and the 6-month assessment. We found a decrease in atypical responsiveness to these stimuli for the sensorimotor enrichment group (mean change $=-0.29$ ), relative to standard care alone (mean change $=0.07)$, but that difference did not reach statistical significance ( $t$ test, $t(24)=-0.36, p=.07)$. Note that a decrease in this score denotes a decrease in autism severity.

The Expressive One-Word Picture Vocabulary Test revealed no difference in outcomes between the groups on this test (ANCOVA, $t(25)=0.16, p=.44$; mean change $=4.77$ for sensorimotor enrichment group; mean change $=4.67$ for standard care group), with both groups improving in this measure over the 6-month period.

\section{Discussion}

We found that an in-home 6-month sensorimotor enrichment therapy produced improvements in cognition and symptom severity in children with autism across a range of ages. Specifically, we have found that environmental enrichment ameliorated autism symptoms for many children both in terms of overall severity and their cognitive performance. In the Expressive One-Word Picture Vocabulary Test, both groups improved, with no statistical difference observed when the two groups were compared.

There were a number of factors that would be expected to increase the variability in the outcomes of this study. For example, we imagine that parents varied in their faithfulness in administering the stimulation. Some children varied in their mood from test to retest. The behavioral outcome measures could be inexact. The 


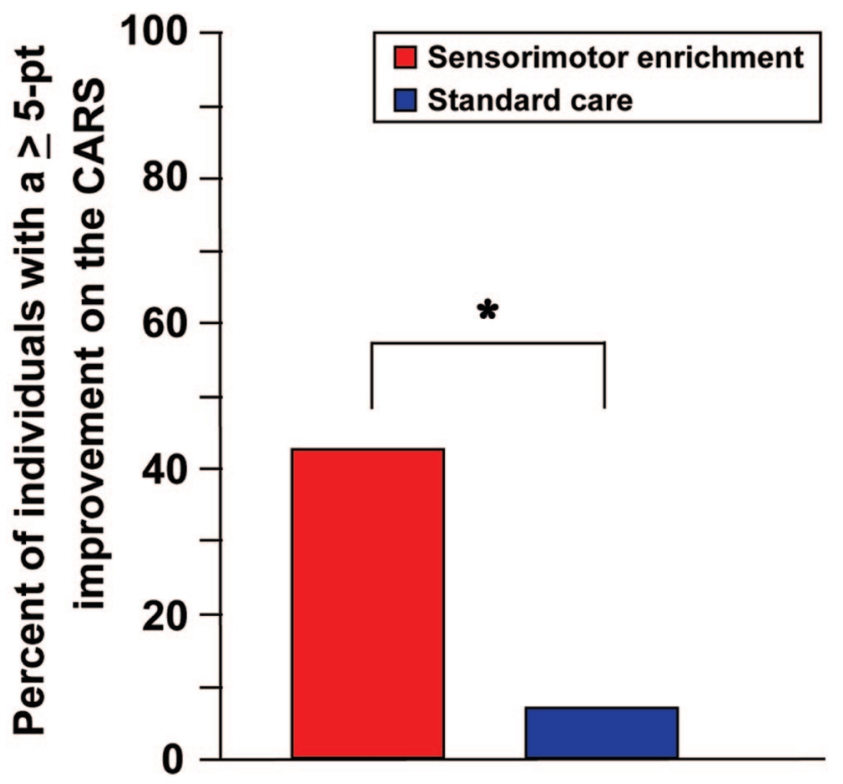

Figure 2. Percent of individuals with clinical improvement on the Childhood Autism Rating Scale (CARS). Sensory enrichment results in improvements in maladaptive behaviors characteristic of individuals with autism. Autism severity was assessed using the Childhood Autism Rating Scale. A clinically significant improvement of at least 5 points on that scale was observed in $42 \%$ of the sensorimotor enrichment group and only $7 \%$ of the standard care group. ${ }^{*}$ Two-sample test for proportions, $p=.03$.

children had a wide age range, their symptoms varied widely, and we tested a relatively small number of subjects who had a variety of concurrent standard therapies. The fact that we were able to reveal consistent significant differences between the groups despite these sources of variability, suggests that there is a strong effect of environmental enrichment on these children.

\section{Comparison to Other Autism Treatments}

Sensory integration therapy is often used by occupational therapists to treat children with autism (Ayres \& Tickle, 1980). The treatment typically involves vestibular, proprioceptive, auditory, and tactile inputs using brushes, swings, and balls, although other senses may be engaged at the discretion of the therapist. While attempts to use sensory integration therapy for autism have typically not been successful (Baranek, 2002; Dawson \& Watling, 2000), a recent pilot study found some improvements in "autistic mannerisms" using that approach for children with autism (Pfeiffer, Koenig, Kinnealey, Sheppard, \& Henderson, 2011).

Applied behavior analysis is a widely used treatment for autism. This approach uses discrete trial teaching, in which therapists break down behaviors into their basic components, rewarding positive performance, and then generalizing skills to other situations (Lovaas, 1987). Typically, a child will receive this therapy from a trained professional for 25-40 hours/week for a number of years. Meta-analyses regarding its efficacy, however, are not in full agreement (Ospina et al., 2008; Smith, Groen, \& Wynn, 2000; Spreckley \& Boyd, 2009; Rogers \& Vismara, 2008). The Early Start Denver Model uses applied behavior analysis techniques, but also encourages positive affect and shared engagement between the therapist and child (Dawson et al., 2010). The Agency for Health Care Research and Quality recently evaluated the data supporting both applied behavior analysis and the Denver Model, and concluded that "... improvements occur in some aspects of language, cognitive ability, adaptive behavior, challenging behaviors, and potentially, educational attainment, for some children" (Warren et al., 2011).

Children given the Denver Model treatment have shown gains in cognitive performance of about 10 IQ points, comparable to what we have found, along with gains in autism severity, also as we have found. They also reported improvements in adaptive behavior, communication, and motor skills, although they did not find differences in repetitive behavior and ADOS scores (Dawson et al., 2010).

Differences between the Denver Model and the environmental enrichment therapy described here include the fact that the children in the Denver treatment started their intensive therapy between 18 and 30 months, while the children in our study averaged 6.6 years old. Early detection of autism is still not common (Pringle, Colpe, Blumberg, Avila, \& Kogan, 2012), despite the call by the American Academy of Pediatrics for physicians to screen 18-month-old children for autism (Johnson \& Myers, 2007). In fact, the median age at which children are diagnosed with autism in the U.S. is 5 years old (Pringle et al., 2012). This situation may limit the efficacy of the intensive behavioral approaches, because such behavioral treatments do not seem to be very effective for even 4-7-year-old children (Eikeseth, Smith, Jahr, \& Eldevik, 2002).

The Denver Model also took 20.4 hours/week of professional treatment and 16.3 hours/week of parental treatment over the course of 2 years, while the environmental enrichment used in our
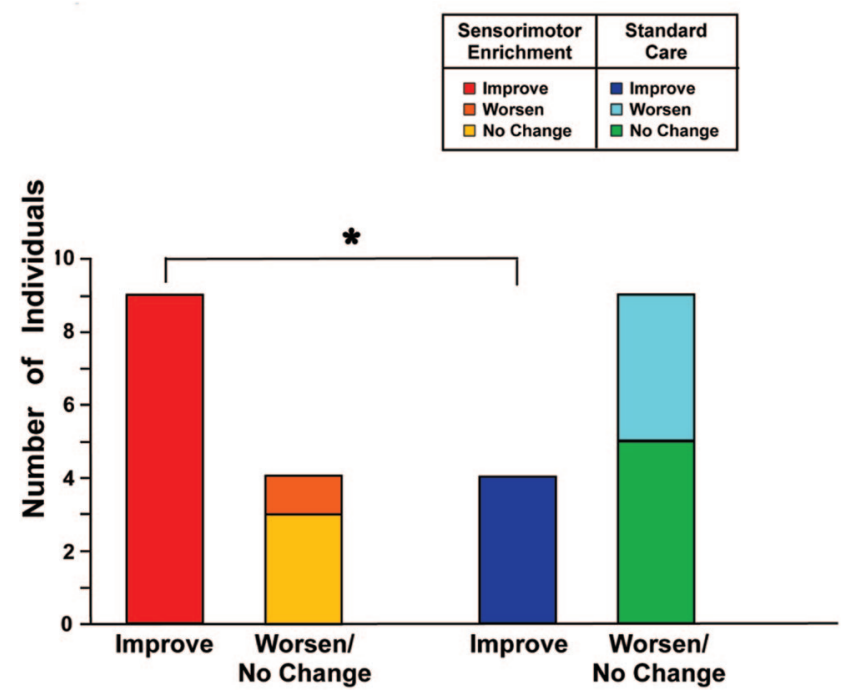

Figure 3. Parental assessment of autism behaviors. Parents were asked to characterize autism behaviors over the course of the study as having improved, worsened, or had no change. In the sensorimotor enrichment group, $69 \%$ of parents expressed an improvement in overall autism symptoms, compared to $31 \%$ in the standard care group, corroborating the statistically significant improvement in overall Childhood Autism Rating Scale scores in the enrichment therapy group relative to the standard care control group. ${ }^{*}$ Two-sample test for proportions, $p=.03$. 
study took about 5-9 hours/week of parental treatment for 6 months. The total cost in time and money of the Denver Model is therefore high relative to the cost of the environmental enrichment program presented in this report. Applied behavior analysis is also quite expensive; the original Lovaas study scheduled 40 hours of professional treatment/week, although less intensive programs also have reported improvements in children with autism (Smith et al., 2000; Fernell et al., 2011).

\section{Developmental Trajectories}

The developmental trajectories of 6,975 children with autism, aged 2-14, were determined over repeated assessments using group-based latent trajectory modeling and multinomial logistic regression models (Fountain, Winter, \& Bearman, 2012). The researchers found that the children clustered into several groups. Those with a low initial autism severity tended to have the greatest improvements over time. Most children who were initially assessed with intellectual disabilities did not see much improvement, although about $10 \%$ of children improved from having a severe autism assessment to being high functioning. Although the outcomes of this environmental enrichment trial cannot be compared directly to the Fountain et al., developmental trajectory report, enriched sensorimotor experiences appear to have improved the developmental trajectory for a significant proportion of children with autism in our study.

\section{Neural Pathways}

Olfactory dysfunction is associated with neural atrophy in specific brain areas (Bitter et al., 2010, 2011). The affected areas include the nucleus accumbens, medial and dorsolateral prefrontal cortex, piriform cortex, insular cortex, orbitofrontal cortex, hippocampus, parahippocampal gyrus, supramarginal gyrus, and cerebellum. Olfactory system dysgenesis has been suggested to underlie the development of autism (Brang \& Ramachandran, 2010), and remarkably, every area of the brain that is affected following olfactory deprivation is also adversely affected in the autistic brain (Allen \& Courchesne, 2003; Anderson et al., 2010; Baron-Cohen et al., 1999; Courchesne, 1997; Gilbert, Bird, Brindley, Frith, \& Burgess, 2008; Gilbert, Meuwese, Towgood, Frith, \& Burgess, 2009; Hadjikhani, Joseph, Snyder, \& Tager-Flusberg, 2006; Hasan, Walimuni, \& Frye, 2012; Richey et al., 2012; Schumann et al., 2004; Yu, Cheung, Chua, \& McAlonan, 2011). It therefore seems possible that limited olfactory experiences during development may contribute to the inability of individuals to compensate for the neural and behavioral anomalies produced by autism, or it may even contribute directly to their neural anomalies.

\section{Norepinephrine}

While neither olfactory stimulation nor tactile stimulation evoked much of a noradrenergic response in young rats, the combination of those stimuli evoked a $\sim 300 \%$ increase in norepinephrine that did not return to baseline levels for 2 hours (Rangel \& Leon, 1995). This rise in norepinephrine is critical for both the neural and the behavioral consequences of early olfactory learning in rats (Sullivan et al., 1989; Sullivan, Wilson, Lemon, \& Gerhardt, 1994; Sullivan, Stackenwalt, Nasr, Lemon, \& Wilson,
2000). Mice housed in an enriched environment also have elevated norepinephrine levels in their brains (Naka, Shiga, Yaguchi, \& Okado, 2002) and the effects of environmental enrichment also depend on this rise in norepinephrine (Mohammed, Jonsson, \& Archer, 1986; Veyrac et al., 2009; Li et al., 2013).

Some children with autism may have systemic deficient noradrenergic responses that may impair their ability to compensate for their neurological issues. Time-averaged measures of norepinephrine in urine, which are not affected by the stress of a blood draw, found chronically depressed levels of that neurotransmitter in children with autism (Barthelemy, et al., 1988; Young, Cohen, Brown, \& Caparulo, 1978). The mothers of autistic children also have depressed dopamine beta-hydroxylase that results in depressed maternal norepinephrine levels during pregnancy that could affect the neural development of their child (Robinson, Schutz, Macciardi, White, \& Holden, 2001). Other studies suggest an increase in norepinephrine in children with autism (Anderson, Colombo, \& Unruh, 2012). Since the effects of norepinephrine on learning describe an inverted U-shaped function (Baldi \& Bucharelli, 2005), with either low or high levels preventing neurobehavioral plasticity, it seems possible that enriched sensory stimulation may have normalized the norepinephrine response in these children, thereby allowing neural plasticity to proceed.

How might norepinephrine facilitate functional compensation in the brains of children with autism? Norepinephrine stimulates BDNF production (Chen, Nguyen, Pike, \& Russo-Neustadt, 2007; Mannari et al., 2008), which is low in autistic individuals (Sheikh et al., 2010), increases neurogenesis, (Jhaveri et al., 2010; Masuda et al., 2012), increases brain glutamate and dopamine (Grinberg, Rueb, \& Heinsen, 2011), and downregulates inflammatory genes (Feinstein et al., 2002; Heneka et al., 2003). It also prevents neuronal death (Counts \& Mufson, 2010; Patel, Chen, \& RussoNeustadt, 2010), in part by decreasing oxidative stress (Traver et al., 2005; Troadec et al., 2001). Robertson (2013) has suggested that repeated noradrenergic pulses over the course of a lifetime build up a compensatory mechanism that protects aged individuals from the dementia associated with Alzheimer's disease, even when they express its characteristic neuropathology. This concept is similar to what we are proposing for autism, except that the compensatory mechanisms would develop to improve preexisting autism symptoms.

\section{Future Studies}

We hope to determine in future studies whether there is an amelioration of the sensory processing dysfunction that commonly affects children with autism and whether there is a correlation between the cognitive and behavior improvements and changes in sensory processing dysfunction using a more sophisticated measure for those responses. We also predict that regular treatment in school by a trained therapist would improve the outcomes for the children by assuring that they received the treatment reliably. It will be important to determine whether the sensorimotor enrichment therapy can be used only in an adjunctive way, or whether it can be used successfully on its own. If sensory enrichment can be effective on its own, it would be a less expensive and less timeconsuming therapeutic option that can be used successfully for older children. Such a monotherapy would be beneficial to children, parents, insurers, and society (Ganz, 2007). Indeed, individ- 
ual cases that we have observed suggest that this therapy is just as effective when used in the absence of any other treatment. It also will be important to understand who may benefit from this approach and who may not, and to study the possible role of norepinephrine in mediating improvements in autistic symptoms. Finally, we would like to determine whether these improvements are long-lasting, whether initiation of the enrichment at 18 months of age would further enhance its efficacy, and whether continued sensorimotor enrichment therapy results in further behavioral and cognitive improvements.

\section{References}

Abrahams, B. S., \& Geschwind, D. H. (2008). Advances in autism genetics: On the threshold of a new neurobiology. Nature Reviews Genetics, 9, 341-355. doi:10.1038/nrg2346

Allen, G., \& Courchesne, E. (2003). Differential effects of developmental cerebellar abnormality on cognitive and motor functions in the cerebellum: An fMRI study of autism. The American Journal of Psychiatry, 160, 262-273. doi:10.1176/appi.ajp.160.2.262

Anderson, C. J., Colombo, J., \& Unruh, K. E. (2012). Pupil and salivary indicators of autonomic dysfunction in autism spectrum disorder. Developmental Psychobiology. Advance online publication. doi:10.1002/ dev. 21051

Anderson, J. S., Lange, N., Froehlich, A., DuBray, M. B., Druzgal, T. J., Froimowitz, M. P., . . . Lainhart, J. E. (2010). Decreased left posterior insular activity during auditory language in autism. American Journal of Neuroradiology, 31, 131-139. doi:10.3174/ajnr.A1789

Ayres, A. J., \& Tickle, L. S. (1980). Hyper-responsivity to touch and vestibular stimuli as a predictor of positive response to sensory integration procedures by autistic children. American Journal of Occupational Therapy, 34, 375-381. doi:10.5014/ajot.34.6.375

Baldi, E., \& Bucherelli, C. (2005). The inverted "u-shaped" dose-effect relationships in learning and memory: Modulation of arousal and consolidation. Nonlinearity in Biology, Toxicology, Medicine, 3, 9-21. doi:10.2201/nonlin.003.01.002

Baranek, G. T. (2002). Efficacy of sensory and motor interventions for children with autism. Journal of Autism and Developmental Disorders, 32, 397-422. doi:10.1023/A:1020541906063

Baron-Cohen, S., Ring, H. A., Wheelwright, S., Bullmore, E. T., Brammer, M. J., Simmons, A., \& Williams, S. C. R. (1999). Social intelligence in the normal and autistic brain: An fMRI study. European Journal of Neuroscience, 11, 1891-1898. doi:10.1046/j.1460-9568.1999.00621.x

Barthelemy, C., Bruneau, N., Cottet-Eymard, J. M., Domenech-Jouve, J., Garreau, B., Lelord, G., . . . Peyrin, L. (1988). Urinary free and conjugated catecholamines and metabolites in autistic children. Journal of Autism and Developmental Disorders, 18, 583-591. doi:10.1007/ BF02211876

Bengoetxea, H., Ortuzar, N., Bulnes, S., Rico-Barrio, I., Lafuente, J. V., \& Argandoña, E. G. (2012). Enriched and deprived sensory experience induces structural changes and rewires connectivity during the postnatal development of the brain. Neural Plasticity, 2012, article 305693. doi: $10.1155 / 2012 / 305693$

Bennetto, L., Kuschner, E. S., \& Hyman, S. L. (2007). Olfaction and taste in autism. Biological Psychiatry, 62, 1015-1021. doi:10.1016/j.biopsych .2007.04.019

Ben-Sasson, A., Hen, L., Fluss, R., Cermak, S. A., Engel-Yeger, B., \& Gal, E. (2009). A meta-analysis of sensory modulation symptoms in individuals with autism spectrum disorders. Journal of Autism and Developmental Disorders, 39, 1-11. doi:10.1007/s10803-008-0593-3

Bitter, T., Gudziol, H., Burmeister, H. P., Mentzel, H. J., Guntinas-Lichius, O., \& Gaser, C. (2010). Anosmia leads to a loss of gray matter in cortical brain areas. Chemical Senses, 35, 407-415. doi:10.1093/chemse/bjq028
Bitter, T., Siegert, F., Gudziol, H., Burmeister, H. P., Mentzel, H. J., Hummel, T., . . Guntinas-Lichius, O. (2011). Gray matter alterations in parosmia. Neuroscience, 177, 177-182. doi:10.1016/j.neuroscience .2011.01.016

Brang, D., \& Ramachandran, V. S. (2010). Olfactory bulb dysgenesis, mirror neuron system dysfunction, and autonomic dysregulation as the neural basis for autism. Medical Hypotheses, 74, 919-921. doi:10.1016/ j.mehy.2008.11.048

Calhoun, J. B. (1950). The study of wild animals under controlled conditions. Annals of the New York Academy of Sciences, 51, 1113-1122. doi:10.1111/j.1749-6632.1950.tb27339.x

Chen, M. J., Nguyen, T. V., Pike, C. J., \& Russo-Neustadt, A. A. (2007). Norepinephrine induces BDNF and activates the PI-3K and MAPK cascades in embryonic hippocampal neurons. Cellular Signalling, 19, 114-128. doi:10.1016/j.cellsig.2006.05.028

Coopersmith, R., \& Leon, M. (1984). Enhanced neural response to familiar olfactory cues. Science, 225, 849-851. doi:10.1126/science.6474157

Counts, S. E., \& Mufson, E. J. (2010). Noradrenaline activation of neurotrophic pathways protects against neuronal amyloid toxicity. Journal of Neurochemistry, 113, 649-660. doi:10.1111/j.1471-4159.2010 .06622.x

Courchesne, E. (1997). Brainstem, cerebellar and limbic neuroanatomical abnormalities in autism. Current Opinion in Neurobiology, 7, 269-278. doi:10.1016/S0959-4388(97)80016-5

Dawson, G., Rogers, S., Munson, J., Smith, M., Winter, J., Greenson, J., ... Varley, J. (2010). Randomized, controlled trial of an intervention for toddlers with autism: The Early Start Denver Model. Pediatrics, 125, e17-e23. doi:10.1542/peds.2009-0958

Dawson, G., \& Watling, R. (2000). Interventions to facilitate auditory, visual, and motor integration in autism: A review of the evidence. Journal of Autism and Developmental Disorders, 30, 415-421. doi: 10.1023/A: 1005547422749

Eikeseth, S., Smith, T., Jahr, E., \& Eldevik, S. (2002). Intensive behavioral treatment at school for 4- to 7-year-old children with autism. A 1-year comparison controlled study. Behavior Modification, 26, 49-68. doi: $10.1177 / 0145445502026001004$

Ellis, B. H., Fisher, P. A., \& Zaharie, S. (2004). Predictors of disruptive behavior, developmental delays, anxiety, and affective symptomatology among institutionally reared Romanian children. Journal of the American Academy of Child \& Adolescent Psychiatry, 43, 1283-1292. doi: 10.1097/01.chi.0000136562.24085.160

Ey, E., Leblond, C. S., \& Bourgeron, T. (2011). Behavioral profiles of mouse models for autism spectrum disorders. Autism Research, 4, 5-16. doi:10.1002/aur.175

Feinstein, D. L., Heneka, M. T., Gavrilyuk, V., Dello Russo, C., Weinberg, G., \& Galea, E. (2002). Noradrenergic regulation of inflammatory gene expression in brain. Neurochemistry International, 41, 357-365. doi: 10.1016/S0197-0186(02)00049-9

Fernell, E., Hedvall, Å., Westerlund, J., Höglund Carlsson, L., Eriksson, M., Barnevik Olsson, M., . . . Gillberg, C. (2011). Early intervention in 208 Swedish preschoolers with autism spectrum disorder. A prospective naturalistic study. Research in Developmental Disabilities, 32, 2092 2101. doi:10.1016/j.ridd.2011.08.002

Fountain, C., Winter, B. A., \& Bearman, P. S. (2012). Six developmental trajectories characterize children with autism. Pediatrics, 129, e1112e1120. doi:10.1542/peds.2011-1601

Freitag, C. M. (2007). The genetics of autistic disorders and its clinical relevance: A review of the literature. Molecular Psychiatry, 12, 2-22. doi:10.1038/sj.mp.4001896

Freitag, C. M., Staal, W., Klauck, S. M., Duketis, E., \& Waltes, R. (2010). Genetics of autistic disorders: Review and clinical implications. European Child and Adolescent Psychiatry, 19, 169-178. doi:10.1007/ s00787-009-0076-x 
Ganz, M. L. (2007). The lifetime distribution of the incremental societal costs of autism. Archives of Pediatric and Adolescent Medicine, 161, 343-349. doi:10.1001/archpedi.161.4.343

Ghoshal, A., Pouget, P., Popescu, M., \& Ebner, F. (2009). Early bilateral sensory deprivation blocks the development of coincident discharge in rat barrel cortex. The Journal of Neuroscience, 29, 2384-2392. doi: 10.1523/JNEUROSCI.4427-08.2009

Gilbert, S. J., Bird, G., Brindley, R., Frith, C. D., \& Burgess, P. W. (2008). Atypical recruitment of medial prefrontal cortex in autism spectrum disorders: An fMRI study of two executive function tasks. Neuropsychologia, 46, 2281-2291. doi:10.1016/j.neuropsychologia.2008.03.025

Gilbert, S. J., Meuwese, J. D. I., Towgood, K. J., Frith, C. D., \& Burgess, P. W. (2009). Abnormal functional specialization within medial prefrontal cortex in high-functioning autism: A multi-voxel similarity analysis. Brain, 132, 869-878. doi:10.1093/brain/awn365

Grinberg, L. T., Rueb, U., \& Heinsen, H. (2011). Brainstem: Neglected locus in neurodegenerative diseases. Frontiers in Neurology, 2, 42. doi:10.3389/fneur.2011.00042

Guthrie, K. M., Wilson, D. A., \& Leon, M. (1990). Early unilateral deprivation modifies olfactory bulb function. Journal of Neuroscience, 10, 3402-3412

Hadjikhani, N., Joseph, R. M., Snyder, J., \& Tager-Flusberg, H. (2006). Anatomical differences in the mirror neuron system and social cognition network in autism. Cerebral Cortex, 16, 1276-1282. doi:10.1093/ cercor/bhj069

Hasan, K. M., Walimuni, I. S., \& Frye, R. E. (2012). Global cerebral and regional multimodal neuroimaging markers of the neurobiology of autism: Development and cognition. Journal of Child Neurology. Advance online publication. doi:10.1177/0883073812452917

Heneka, M. T., Gavrilyuk, V., Landreth, G. E., O’Banion, M. K., Weinberg, G., \& Feinstein, D. L. (2003). Noradrenergic depletion increases inflammatory responses in brain: Effects on IkappaB and HSP70 expression. Journal of Neurochemistry, 85, 387-398. doi:10.1046/j.14714159.2003.01694.x

Hilton, C. L., Harper, J. D., Kueker, R. H., Lang, A. R., Abbacchi, A. M., Todorov, A., \& LaVesser, P. D. (2010). Sensory responsiveness as a predictor of social severity in children with high functioning autism spectrum disorders. Journal of Autism and Developmental Disorders, 40, 937-945. doi:10.1007/s10803-010-0944-8

Hoksbergen, R., ter Laak, J., Rijk, K., van Dijkum, C., \& Stoutjesdijk, F. (2005). Post-institutional autistic syndrome in Romanian adoptees. Journal of Autism and Developmental Disorders, 35, 615-623. doi:10.1007/ s10803-005-0005-x

Hurst, J. L., \& Barnard, C. (1992). Kinship and social behavior in wild house mice: Effects of social group membership and relatedness on the responses of dominant males toward juveniles. Behavioral Ecology, 3, 196-206. doi:10.1093/beheco/3.3.196

Jhaveri, D. J., Mackay, E. W., Hamlin, A. S., Marathe, S. V., Nandam, L. S., Vaidya, V. A., \& Bartlett, P. F. (2010). Norepinephrine directly activates adult hippocampal precursors via beta3-adrenergic receptors. The Journal of Neuroscience, 30, 2795-2806. doi:10.1523/JNEUROSCI .3780-09.2010

Johnson, C. P., \& Myers, S. M. (2007). Identification and evaluation of children with autism spectrum disorders. Pediatrics, 120, 1183-1215. doi:10.1542/peds.2007-2361

Johnson, R., Browne, K., \& Hamilton-Giachritsis, C. (2006). Young children in institutional care at risk of harm. Trauma, Violence, \& Abuse, 7 , 34-60. doi: $10.1177 / 1524838005283696$

Kern, J. K., Trivedi, M. H., Grannemann, B. D., Garver, C. R., Johnson, D. G., Andrews, A. A., . . S Schroeder, J. L. (2007). Sensory correlations in autism. Autism, 11, 123-134.

Kerr, B., Silva, P. A., Walz, K., \& Young, J. I. (2010). Unconventional transcriptional response to environmental enrichment in a mouse model of Rett syndrome. PloS One, 5, e11534. doi:10.1371/journal.pone .0011534

Kondo, M., Gray, L. J., Pelka, G. J., Christodoulou, J., Tam, P. P., \& Hannan, A. J. (2008). Environmental enrichment ameliorates a motor coordination deficit in a mouse model of Rett syndrome-Mecp2 gene dosage effects and BDNF expression. European Journal of Neuroscience, 27, 3342-3350. doi:10.1111/j.1460-9568.2008.06305.x

Lacaria, M., Spencer, C., Gu, W., Paylor, R., \& Lupski, J. R. (2012). Enriched rearing improves behavioral responses of an animal model for CNV-based autistic-like traits. Human Molecular Genetics, 21, 30833096. doi:10.1093/hmg/dds124

Lane, A. E., Young, R. L., Baker, A. E., \& Angley, M. T. (2010). Sensory processing subtypes in autism: Association with adaptive behavior. Journal of Autism and Developmental Disorders, 40, 112-122.

Laviola, G., Hannan, A. J., Macri, S., Solinas, M., \& Jaber, M. (2008). Effects of enriched environment on animal models of neurodegenerative diseases and psychiatric disorders. Neurobiology of Disorders, 31, 159168. doi:10.1016/j.nbd.2008.05.001

Leekam, S. R., Nieto, C., Libby, S. J., Wing, L., \& Gould, J. (2007) Describing the sensory abnormalities of children and adults with autism. Journal of Autism and Developmental Disorders, 37, 894-910. doi 10.1007/s10803-006-0218-7

Li, S., Jin, M., Zhang, D., Yang, T., Koeglsperger, T., Fu, H., \& Selkoe, D. J. (2013). Environmental novelty activates $\beta 2$-adrenergic signaling to prevent the impairment of hippocampal LTP by A $\beta$ oligomers. Neuron, 77, 929-941. doi:10.1016/j.neuron.2012.12.040

Lonetti, G., Angelucci, A., Morando, L., Boggio, E. M., Giustetto, M., \& Pizzorusso, T. (2010). Early environmental enrichment moderates the behavioral and synaptic phenotype of MeCP2 null mice. Biological Psychiatry, 67, 657-665. doi:10.1016/j.biopsych.2009.12.022

Lovaas, O. I. (1987). Behavioral treatment and normal educational and intellectual functioning in young autistic children. Journal of Consulting and Clinical Psychology, 55, 3-9. doi:10.1037/0022-006X.55.1.3

Mannari, C., Origlia, N., Scatena, A., Del Debbio, A., Catena, M., Dell'agnello, G., . . . Piccinni, A. (2008). BDNF level in the rat prefrontal cortex increases following chronic but not acute treatment with duloxetine, a dual acting inhibitor of noradrenaline and serotonin re-uptake. Cellular and Molecular Neurobiology, 28, 457-468. doi: 10.1007/s10571-007-9254-x

Masuda, T., Nakagawa, S., Boku, S., Nishikawa, H., Takamura, N., Kato, A., . . . Koyama, T. (2012). Noradrenaline increases neural precursor cells derived from adult rat dentate gyrus through beta2 receptor. Progress in Neuro-Psychopharmacology \& Biological Psychiatry, 36, $44-$ 51. doi:10.1016/j.pnpbp.2011.08.019

Maya-Vetencourt, J. F., \& Origlia, N. (2012). Visual cortex plasticity: A complex interplay of genetic and environmental influences. Neural Plasticity, 2012, article 631965. doi:10.1155/2012/631965

Miller, L., Chan, W., Comfort, K., \& Tirella, L. (2005). Health of children adopted from Guatemala: Comparison of orphanage and foster care. Pediatrics, 115, e710-717. doi:10.1542/peds.2004-2359

Mohammed, A. K., Jonsson, G., \& Archer, T. (1986). Selective lesioning of forebrain noradrenaline neurons at birth abolishes the improved maze learning performance induced by rearing in complex environment. Brain Research, 398, 6-10. doi:10.1016/0006-8993(86)91243-6

Nag, N., Moriuchi, J. M., Peitzman, C. G., Ward, B. C., Kolodny, N. H., \& Berger-Sweeney, J. E. (2009). Environmental enrichment alters locomotor behaviour and ventricular volume in Mecp $2^{1 \text { lox }}$ mice. Behavioural Brain Research, 196, 44-48. doi:10.1016/j.bbr.2008.07.008

Naka, F., Shiga, T., Yaguchi, M., \& Okado, N. (2002). An enriched environment increases noradrenaline concentration in the mouse brain Brain Research, 924, 124-126. doi:10.1016/S0006-8993(01)03257-7

Nelson, C. A., Zeanah, C. H., Fox, N. A., Marshall, P. J., Smyke, A. T., \& Guthrie, D. (2007). Cognitive recovery in socially deprived young 
children: The Bucharest Early Intervention Project. Science, 318, 19371940. doi:10.1126/science.1143921

Nithianantharajah, J., \& Hannan, A. J. (2006). Enriched environments, experience-dependent plasticity and disorders of the nervous system. Nature Reviews Neuroscience, 7, 697-709. doi:10.1038/nrn1970

Noppeney, U. (2007). The effects of visual deprivation on functional and structural organization of the human brain. Neuroscience and Biobehavioral Review, 31, 1169-1180. doi:10.1016/j.neubiorev.2007.04.012

Ospina, M. B., Krebs Seida, J., Clark, B., Karkhaneh, M., Hartling, L., Tjosvold, L., . . . Smith, V. (2008). Behavioural and developmental interventions for autism spectrum disorder: A clinical systematic review. PLoS ONE, 3, e3755. doi:10.1371/journal.pone.0003755

Pang, T. Y., \& Hannan, A. J. (2013). Enhancement of cognitive function in models of brain disease through environmental enrichment and physical activity. Neuropharmacology, 64, 515-528. doi:10.1016/j.neuropharm .2012 .06 .029

Patel, N. J., Chen, M. J., \& Russo-Neustadt, A. A. (2010). Norepinephrine and nitric oxide promote cell survival signaling in hippocampal neurons. European Journal of Pharmacology, 633, 1-9. doi:10.1016/j.ejphar .2010 .01 .012

Perry, P., Cummings, A., Geier, J. D., Freeman, N. L., Hughes, S., LaRose, L., . . . Williams, J. (2008). Effectiveness of intensive behavioral intervention in a large, community-based program. Research in Autism Spectrum Disorders, 2, 621-642. doi:10.1016/j.rasd.2008.01.002

Pfeiffer, B. A., Koenig, K., Kinnealey, M., Sheppard, M., \& Henderson, L. (2011). Effectiveness of sensory integration interventions in children with autism spectrum disorders: A pilot study. American Journal of Occupational Therapy, 65, 76-85. doi:10.5014/ajot.2011.09205

Potocki, L., Bi, W., Treadwell-Deering, D., Carvalho, C. M., Eifert, A., Friedman, E. M., . . . Lupski, J. R. (2007). Characterization of PotockiLupski syndrome (dup(17)(pp11.2p11.2)) and delineation of a dosagesensitive critical interval that can convey an autism phenotype. The American Journal of Human Genetics, 80, 633-649. doi:10.1086/ 512864

Pringle, B. A., Colpe, L. J., Blumberg, S. J., Avila, R. M., \& Kogan, M. D. (2012). Diagnostic history and treatment of school-aged children with autism spectrum disorder and special health care needs. NCHS Data Brief No. 97. Hyattsville, MD: National Center for Health Statistics. Retrieved from http://www.cdc.gov/nchs/data/databriefs/db97.pdf

Rangel, S., \& Leon, M. (1995). Early odor preference training increases olfactory bulb norepinephrine. Developmental Brain Research, 85, 187191. doi:10.1016/0165-3806(94)00211-H

Restivo, L., Ferrari, F., Passino, E., Sgobio, C., Bock, J., Oostra, B. A., Ammassari-Teule, M. (2005). Enriched environment promotes behavioral and morphological recovery in a mouse model for the fragile $\mathrm{X}$ syndrome. Proceedings of the National Academies of Science, USA, 102, 11557-11562.

Richey, J. A., Rittenberg, A., Hughes, L., Damiano, C. A., Sabatino, A., Miller, S., . . . Dichter, G. S. (2012). Common and distinct neural features of social and nonsocial reward processing in autism and social anxiety disorder. Social, Cognitive and Affective Neuroscience. Advance online publication. doi:10.1093/scan/nss146

Robertson, I. H. (2013). A noradrenergic theory of cognitive reserve: Implications for Alzheimer's disease. Neurobiology of Aging, 34, $298-$ 308. doi:10.1016/j.neurobiolaging.2012.05.019

Robinson, P. D., Schutz, C. K., Macciardi, F., White, B. N., \& Holden, J. J. (2001). Genetically determined low maternal serum dopamine betahydroxylase levels and the etiology of autism spectrum disorders. American Journal of Medical Genetics, 100, 30-36. doi:10.1002/ajmg.1187

Rogers, S. J., \& Vismara, L. A. (2008). Evidence-based comprehensive treatments for early autism. Journal of Clinical Child and Adolescent Psychology, 37, 8-38. doi:10.1080/15374410701817808

Schneider, T., Turczak, J., \& Przewlocki, R. (2006). Environmental enrichment reverses behavioral alterations in rats prenatally exposed to valproic acid: Issues for a therapeutic approach in autism. Neuropsychopharmacology, 31, 36-46.

Schoen, S. A., Miller, L. J., Brett-Green, B. A., \& Nielsen, D. M. (2009). Physiological and behavioral differences in sensory processing: A comparison of children with Autism Spectrum Disorder and Sensory Modulation Disorder. Frontiers in Integrative Neuroscience, 3, article 29 doi:10.3389/neuro.07.029.2009

Schopler, E., Reichler, R. J., DeVellis, R. F., \& Daly, K. (1980). Toward objective classification of childhood autism: Childhood Autism Rating Scale (CARS). Journal of Autism and Developmental Disorders, 10, 91-103. doi:10.1007/BF02408436

Schumann, C. M., Hamstra, J., Goodlin-Jones, B. L., Lotspeich, L. J., Kwon, H., Buonocore, M. H., . . A Amaral, D. G. (2004). The amygdala is enlarged in children but not adolescents with autism; the hippocampus is enlarged at all ages. Journal of Neuroscience, 24, 6392-6401. doi: 10.1523/JNEUROSCI.1297-04.2004

Sheikh, A. M., Malik, M., Wen, G., Chauhan, A., Chauhan, V., Gong, C.-X., . . L Li, X. (2010). BDNF-Akt-Bcl2 antiapoptotic signaling pathway is compromised in the brain of autistic subjects. Journal of Neuroscience Research, 88, 2641-2647.

Smith, T., Groen, A. D., \& Wynn, J. W. (2000). Randomized trial of intensive early intervention for children with pervasive developmental disorder. American Journal on Mental Retardation, 105, 269-285. doi: 10.1352/0895-8017(2000) $105<0269$ :RTOIEI $>2.0$. CO;2

Spreckley, M., \& Boyd, R. (2009). Efficacy of applied behavioral intervention in preschool children with autism for improving cognitive, language, and adaptive behavior: A systematic review and metaanalysis. The Journal of Pediatrics, 154, 338-344. doi:10.1016/j.jpeds 2008.09.012

Sullivan, R. M., Stackenwalt, G., Nasr, F., Lemon, C., \& Wilson, D. A. (2000). Association of an odor with activation of olfactory bulb noradrenergic beta-receptors or locus coeruleus stimulation is sufficient to produce learned approach responses to that odor in neonatal rats. Behavioral Neuroscience, 114, 957-962. doi:10.1037/0735-7044.114.5 .957

Sullivan, R. M., Taborsky-Barba, S., Mendoza, R., Itano, A., Leon, M., Cotman, C. W., . . . Lott, I. (1991). Olfactory classical conditioning in neonates. Pediatrics, 87, 511-518.

Sullivan, R. M., Wilson, D. A., Lemon, C., \& Gerhardt, G. A. (1994). Bilateral 6-OHDA lesions of the locus coeruleus impair associative olfactory learning in newborn rats. Brain Research, 643, 306-309. doi:10.1016/0006-8993(94)90038-8

Sullivan, R. M., Wilson, D. A., \& Leon, M. (1989). Norepinephrine and learning-induced plasticity in infant rat olfactory system. Journal of Neuroscience, 9, 3998-4006.

Teal, M. B., \& Wiebe, M. J. (1986). A validity analysis of selected instruments used to assess autism. Journal of Autism and Developmental Disorders, 16, 485-494. doi:10.1007/BF01531713

Tomchek, S. D., \& Dunn, W. (2007). Sensory processing in children with and without autism; A comparative study using the short sensory profile. American Journal of Occupational Therapy, 61, 190-200. doi:10.5014/ ajot.61.2.190

Traver, S., Salthun-Lassalle, B., Marien, M., Hirsch, E. C., Colpaert, F., \& Michel, P. P. (2005). The neurotransmitter noradrenaline rescues septal cholinergic neurons in culture from degeneration caused by low-level oxidative stress. Molecular Pharmacology, 67, 1882-1891. doi:10.1124/ mol.104.007864

Troadec, J. D., Marien, M., Darios, F., Hartmann, A., Ruberg, M., Colpaert, F., \& Michel, P. P. (2001). Noradrenaline provides long-term protection to dopaminergic neurons by reducing oxidative stress. Journal of Neurochemistry, 79, 200-210. doi:10.1046/j.1471-4159.2001 $.00556 . \mathrm{x}$

Tsatsanis, K. D., Dartnall, N., Cicchetti, D., Sparrow, S. S., Klin, A., \& Volkmar, F. R. (2003). Concurrent validity and classification accuracy 
of the Leiter and Leiter-R in low-functioning children with autism. Journal of Autism and Developmental Disorders, 33, 23-30. doi:10 .1023/A:1022274219808

van Praag, H., Kempermann, G., \& Gage, F. H. (2000). Neural consequences of environmental enrichment. Nature Reviews Neuroscience, 1 , 191-198. doi:10.1038/35044558

Veyrac, A., Sacquet, J., Nguyen, V., Marien, M., Jourdan, F., \& Didier, A. (2009). Novelty determines the effects of olfactory enrichment on memory and neurogenesis through noradrenergic mechanisms. Neuropsychopharmacology, 34, 786-795. doi:10.1038/npp.2008.191

Warren, Z., Veenstra-VanderWeele, J., Stone, W., Bruzek, J. L., Nahmias, A. S., Foss-Feig, J. H., . . McPheeters, M. L. (2011). Therapies for children with autism spectrum disorders: Comparative effectiveness review, 26. Agency for Healthcare Research and Quality. AHRQ Publication No. 11-EHC029-EF, Retrieved from http://effectivehealthcare .ahrq.gov/ehc/products/106/651/Autism_Disorder_exec-summ.pdf

Watling, R. L., Deitz, J., \& White, O. (2001). Comparison of Sensory Profile scores of young children with and without autism spectrum disorders. American Journal of Occupational Therapy, 55, 416-423. doi:10.5014/ajot.55.4.416

Wilson, D. A., Sullivan, R. M., \& Leon, M. (1987). Single-unit analysis of postnatal olfactory learning: Modified olfactory bulb output response patterns to learned attractive odors. Journal of Neuroscience, 7, 31543162.
Wismer Fries, A. B., Ziegler, T. E., Kurian, J. R., Jacoris, S., \& Pollak, S. D. (2005). Early experience in humans is associated with changes in neuropeptides critical for regulating social behavior. Proceedings of the National Academies of Science, USA, 102, 17237-17240.

Woo, C. C., Coopersmith, R., \& Leon, M. (1987). Localized changes in olfactory bulb morphology associated with early olfactory learning. Journal of Comparative Neurology, 263, 113-125. doi:10.1002/cne .902630110

Woo, C. C., \& Leon, M. (1991). Increase in a focal population of juxtaglomerular cells in the olfactory bulb associated with early learning. Journal of Comparative Neurology, 305, 49-56. doi:10.1002/cne .903050106

Young, J. G., Cohen, D. J., Brown, S. L., \& Caparulo, B. S. (1978). Decreased urinary free catecholamines in childhood autism. Journal of the American Academy of Child Psychiatry, 17, 671-678. doi:10.1016/ S0002-7138(09)61019-0

Yu, K. K., Cheung, C., Chua, S. E., \& McAlonan, G. M. (2011). Can Asperger syndrome be distinguished from autism? An anatomic likelihood meta-analysis of MRI studies. Journal of Psychiatry \& Neuroscience, 36, 412-421. doi:10.1503/jpn.100138

Received October 22, 2012

Revision received April 3, 2013

Accepted April 12, 2013 